\title{
Harvesting of Plants According Ethnomedicinal Culture of Nso Tribe, Cameroon
}

\author{
Eustace Bonghan Berinyuy* \\ Faculty of Medicine and Biomedical Sciences, University of Yaoundé, Africa
}

*Corresponding author: Eustace Bonghan Berinyuy, Faculty of Medicine and Biomedical Sciences, University of Yaoundé, Cameroon.

To Cite This Article: Eustace Bonghan Berinyuy. Harvesting of Plants According Ethnomedicinal Culture of Nso Tribe, Cameroon. Am J Biomed Sci \& Res. 2019 - 3(5). AJBSR.MS.ID.000706. DOI: 10.34297/AJBSR.2019.03.000706

Received: June 21, 2019 | Published: July 03, 2019

\section{Opinion}

The firm beliefs of the rural community of the Nso ethnic tribe in the powers and role of plant especially medicinal plants can be used to develop a model for harvesting plants. Their belief systems enable several spiritual cultures like Islam, Christianity, African traditional religion etc. to coexist with each other happily for centuries without major crisis. The belief system differs from science, but all scientific principles are taken care off with different justifications. All plants belong to God and is therefore, necessary to ask God permission to use plants by means of prayers. These prayers are said before harvesting medicinal plants. Traditional rites are performed before falling down trees with economic values like colanuts (Cola acuminate), kirah (Prunus africana) etc. It's interesting that even the highly educated or elites would not build a house where economic trees like cola nuts or medicinal plants needs to be destroyed without consulting traditional medicine practitioners. It's very difficult to find an adult without any basic knowledge of traditional medicines especially in treating simple ailments like wounds, stomach upsets, fever etc.

The Nso people believe that there is a balance between the harmful and curative powers of medicinal plants and they pray to the ancestral spirits to swing this balance towards healing (depending on the intention) in case of treatment and away from harm. Mbaiti (Aguaria salicifolia) is one of such plants believed to have mystical powers and has a code of conduct to be observed for healers who harvest any portion of the plant else the person harvesting will not return safely during the harvest and its always strictly adhered to. The traditional medicine practitioners pray to the east, because they believe that there is a connection between God and the sun, both during and after collection, preparation and administration. Traditional healers place a little salt, gift items or even money at the base of the first plant set to be collected (there is always an order in collection and handling of plants, and some combination don't go together). Some people have to be initiated before they can harvest some particular plants.in 1990s there was a communal crisis that caused the lives of people for carrying a particular leaf without due process of traditional rites. Collection is usually in the morning before midday and in the afternoon after noon. it's believed that the gods pass during the midday and receives the items at the base of the plants and also blesses the healers. it's not advisable to collect any plants during midday, a time reserved just for the gods. Collection is always done such that the plant does not die.

The time of the day, particular months and the period of the year are important to traditional healers for the collection of plants. The week has eight traditional days and a particular is reserved for traditional sacrifices and collection of plants is not allowed. There are some plants that needs initiation rites to empower for the collection or holding of the plants and some are not even permitted in private residencies. It's thought that the best collection material is at full moon, because there is believed to be a connection between the phase of the moon and the plant biology. In Nso, the healers classify plants as "principal" plants (which may be used alone) and "secondary" plants which must be mixed with a principal plant and others are just contributors. Collection is usually done by an association of healers that come together to treat particular illness or belong to the same secret societies or cult although individual still collects the plants. Cure duration varies from three to seven days or more though it depends on the ailments. The practices are diversified like in the case of bone fracture the leg of a fowl is broken at the same area of the fracture and treated as well with the plant mixture. The time the fowls starts moving gives an idea about the duration of treatment. When the fowls recover and walk away then the patient will soon follow suit. The traditional medicine in the Nso tribe is highly specialize there are diviners or spiritualist, herbalist, gardeners, healers for particular diseases and even errand boys. Collection of medicinal plants in Nso is a highly technical job and not as simple as it appears. (Personal communication and interaction with Nso, tradional practioners). 